\title{
Impact of BMI on Complications of Gastric Endoscopic Submucosal Dissection
}

\author{
Na Young Kim ${ }^{a}$ Hye Sun Lee ${ }^{b}$ Ki-Young Lee ${ }^{a}$ Soyoung Jeon ${ }^{b}$ \\ Seung Yeon Choi ${ }^{\mathrm{a}} \mathrm{Hye} \mathrm{Ji} \mathrm{Joo}^{\mathrm{a}}$ Ji Eun Kim ${ }^{\mathrm{c}}$ So Yeon Kim ${ }^{\mathrm{a}}$ \\ aDepartment of Anesthesiology and Pain Medicine, Anesthesia and Pain Research Institute, Yonsei University \\ College of Medicine, Seoul, Republic of Korea; 'bepartment of Research Affairs, Biostatistics Collaboration Unit, \\ Yonsei University College of Medicine, Seoul, Republic of Korea; 'Department of Anesthesiology and Pain Medicine, \\ Ajou University School of Medicine, Suwon, Republic of Korea
}

\section{Keywords}

BMI · Complication · Endoscopic submucosal dissection ·

Gastric neoplasm

\begin{abstract}
Background: Gastric endoscopic submucosal dissection (ESD) has a high rate of complications. However, it is unclear whether BMI affects ESD complications. We aimed to investigate the impact of BMI on ESD complications. Methods: A total of 7,263 patients who underwent gastric ESD were classified into 3 groups according to the Asia-Pacific classification of BMI: normal (BMI $\left.<23 \mathrm{~kg} / \mathrm{m}^{2}, n=2,466\right)$, overweight (BMI 23-24.9 kg/m² $, n=2,117$ ), and obese (BMI $\geq 25 \mathrm{~kg} / \mathrm{m}^{2}$, $n=2,680)$. Adjusted logistic regression analyses were conducted to assess the association between BMI and ESD complications. Results: Compared to the normal group, a lower incidence of perforation and a higher incidence of pneumonia and leukocytosis were found in the overweight and obese groups, and intra-ESD desaturation and hypertension were more frequent in the obese group. After adjustment for
\end{abstract}

Na Young Kim and Hye Sun Lee contributed equally to this work.

$\begin{aligned} & \text { karger@karger.com } \\ & \text { www.karger.com/ddi }\end{aligned}$
Karger

confounders, the risk of perforation significantly decreased in the overweight (odds ratio $[\mathrm{OR}]=0.24,95 \%$ confidence interval [Cl]: 0.17-0.33) and obese (OR $=0.12,95 \% \mathrm{Cl}: 0.08-$ 0.18 ) groups compared to that in the normal group. Meanwhile, the risk of pneumonia significantly increased in the overweight (OR $=11.04,95 \% \mathrm{Cl}: 6.31-19.31)$ and obese (OR $=10.71,95 \% \mathrm{Cl}: 6.14-18.66)$ groups compared to the normal group. During sedation, the obese group had a significantly increased risk of desaturation (OR $=2.81,95 \% \mathrm{Cl}$ : 1.18-6.69) and hypertension ( $\mathrm{OR}=1.35,95 \% \mathrm{Cl}: 1.11-1.63$ ) compared to the normal group. Conclusions: High BMI was significantly associated with ESD complications. More caution is needed in cases of obese patients undergoing ESD.

(c) 2020 S. Karger AG, Basel

\section{Introduction}

Endoscopic submucosal dissection (ESD) was introduced to overcome the limitations of endoscopic mucosal resection and has become the treatment of choice for 
Fig. 1. Flow diagram of patient selection.

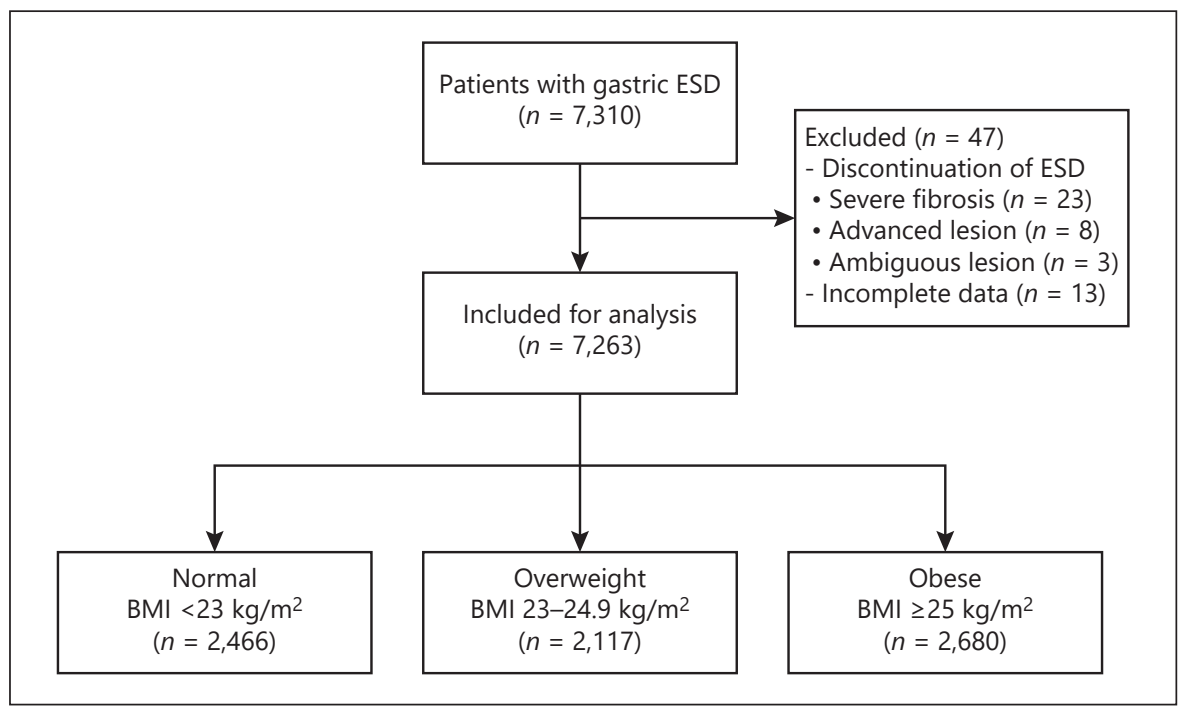
ESD, endoscopic submucosal dissection.

most gastric superficial neoplastic lesions $[1,2]$. ESD was found to have considerable advantages for higher en bloc resection rate and histologically complete resection rate and lower local recurrence rate than endoscopic mucosal resection [3-5]. Despite these advantages, technical difficulties of ESD result in a high frequency of complications, particularly perforation and bleeding [1,6-9]. Moreover, the prolonged procedure time of ESD requires a long sedation time, which may increase respiratory depression and the risk of aspiration pneumonia [8, 9]. Several studies have investigated risk factors for complications (perforation, bleeding, and pneumonia) after ESD and have identified the procedure time, resected size, and the location of the lesion as significant predictors for these complications [6-14]. In addition to these procedure-related factors, patient-related risk factors were found in some studies: liver disease increased perforation [10]; age $\leq 65$ years and $\mathrm{BMI} \geq 25 \mathrm{~kg} / \mathrm{m}^{2}$ increased bleeding $[13,15]$; and age $>75$ years and male sex increased pneumonia [14].

The prevalence of obesity in Asian population is increasing [16] which is reflected in the increasing number of patients who are overweight or obese receiving ESD. Obesity was significantly associated with long procedure time of ESD [17], which implies that obesity can be a contributing factor for complications of ESD. In fact, increasing BMI was associated with an increased frequency of airway maneuver and hypoxemia during sedation for endoscopic retrograde cholangiopancreatography [18]. Conversely, higher BMI decreased the risk of perforation during colonoscopy [19]. On the other hand, studies in- vestigating the association of BMI with the risk of perforation or bleeding in ESD showed inconsistent results [6, $15,17]$. Therefore, it is yet unclear whether BMI affects ESD complications. Hence, this retrospective study aimed to directly assess the impact of BMI on the complications of gastric ESD with a large number of patients.

\section{Patients and Methods}

\section{Patients}

Data from 7,310 patients aged 21-92 years who underwent ESD for gastric neoplasms between September 2010 and December 2018 were accessed from the established electronic medical database in a single center. Of those, 47 patients were excluded for following reasons: discontinuation of ESD due to severe fibrosis $(n=$ $23)$, advanced lesions $(n=8)$, and ambiguous lesions $(n=3)$ or incomplete data $(n=13)$. Finally, 7,263 patients were classified into 3 groups according to the Asia-Pacific classification of BMI: nor$\mathrm{mal}\left(\mathrm{BMI}<23 \mathrm{~kg} / \mathrm{m}^{2}\right.$ ), overweight (BMI $23-24.9 \mathrm{~kg} / \mathrm{m}^{2}$ ), and obese $\left(B M I \geq 25 \mathrm{~kg} / \mathrm{m}^{2}\right.$ ) groups (Fig. 1) [20,21].

\section{Sedation and ESD Procedure}

All procedures were performed by 5 expert endoscopists under sedation with intravenous sedative (propofol or midazolam) alone or in combination with a low-dose opioid (fentanyl or remifentanil). Sedation depth was targeted at minimal or moderate sedation. Standard monitoring included blood pressure, pulse oxygen saturation, capnography, and electrocardiography with respiratory activity. Supplemental oxygen at $3 \mathrm{~L} / \mathrm{min}$ was provided via the nasal cannula. In the left lateral decubitus position, procedures were performed with a standard single-channel upper gastrointestinal endoscope (GIF-Q260J or GIF-H260Z; Olympus Optical, Tokyo, Japan). The area surrounding each lesion was marked using electrocautery (VIO 300D; ERBE, Tübingen, Ger- 
Table 1. Patient characteristics

\begin{tabular}{lcccr}
\hline & $\begin{array}{l}\text { Normal }<23 \mathrm{~kg} / \mathrm{m}^{2} \\
(n=2,466)\end{array}$ & $\begin{array}{l}\text { Overweight } 23-24.9 \mathrm{~kg} / \mathrm{m}^{2} \\
(n=2,117)\end{array}$ & $\begin{array}{l}\text { Obese } \geq 25 \mathrm{~kg} / \mathrm{m}^{2} \\
(n=2,680)\end{array}$ & $p$ value \\
\hline BMI, kg/m & $21.1 \pm 1.5$ & $24.0 \pm 0.6^{*}$ & $27.3 \pm 2.1^{*, \dagger}$ & $<0.001$ \\
Age, years & $64.3 \pm 11.0$ & $63.8 \pm 9.8$ & $63.9 \pm 9.5$ & 0.275 \\
Male sex & $1,583(64.2)$ & $1,553(73.4)^{*}$ & $1,905(71.1)^{*}$ & $<0.001$ \\
ASA physical status & $989(40.1)$ & $736(34.8)^{*}$ & $864(32.2)^{*}$ & $<0.001$ \\
$\quad$ I & $1,157(46.9)$ & $1,033(48.8)$ & $1,347(50.3)$ & 0.056 \\
$\quad$ II & $320(13.0)$ & $348(16.4)^{*}$ & $469(17.5)^{*}$ & $<0.001$ \\
$\quad$ III & $779(31.6)$ & $903(42.7)^{*}$ & $1,423(53.1)^{*, \dagger}$ & $<0.001$ \\
Comorbidities & $364(14.8)$ & $390(18.4)^{*}$ & $582(21.7)^{*} \dagger$ & $<0.001$ \\
$\quad$ Hypertension & $60(2.4)$ & $64(3.0)$ & $109(4.1)^{*}$ & 0.003 \\
$\quad$ Diabetes & $967(39.2)$ & $900(42.5)$ & $1,093(40.8)$ & 0.077 \\
$\quad$ Hepatitis & & & & \\
Current smoker & & & & \\
\hline
\end{tabular}

Values are shown as mean \pm standard deviation or patients, $n(\%)$. ASA, American Society of Anesthesiologists. * Bonferroni-corrected $p<0.05$ compared with the normal group. ${ }^{\dagger}$ Bonferroni-corrected $p<0.05$ compared with the overweight group.

many) with a needle knife (Olympus, Tokyo, Japan) and a saline solution containing epinephrine $(0.01 \mathrm{mg} / \mathrm{mL}) ; 0.8 \%$ indigo carmine was injected into the submucosal layer with a 21-gauge needle to lift the lesion off the muscle layer. A circumferential incision and dissection were performed with a needle knife and an insulated-tip knife (KD-610L, Olympus Optical), respectively. Bleeding or visible vessels were controlled with hemoclips or hemostatic forceps.

\section{Data Collection}

Demographic variables including BMI, age, sex, American Society of Anesthesiologists (ASA) physical status, comorbidities (hypertension, diabetes, and hepatitis), and current smoking status were obtained from electronic medical records. The ESDrelated variables included procedure time, sedation time, recovery time, sedative drugs (propofol, midazolam, or propofol + midazolam whether combined with opioids or not), location of the lesion (upper third, middle third, and lower third of the stomach), gross type of the lesion (elevated, flat, depressed, and unknown), the degree of submucosal fibrosis (endoscopic findings after injection of indigo carmine: F0, no fibrosis, which manifests as a blue transparent layer; F1, mild fibrosis, which appears as a white web-like structure in the blue submucosal layer; and F2, severe fibrosis, which appears as a white muscular structure without a blue transparent layer in the submucosal layer) [13], conduction of en bloc resection (resection occurring in a single piece, as opposed to piecemeal resection in multiple pieces), tumor size (pathologically determined and measured as the highest diameter of the resected specimen), and pathologic diagnosis (cancer or adenoma). Information on sedation-related complications such as desaturation (pulse oxygen saturation $<90 \%$ ), hypertension (need for $\alpha$ - or $\beta$-blocker and calcium channel blocker), and hypotension (need for norepinephrine, ephedrine, and phenylephrine) was collected. In addition, procedure-related complications such as perforation (direct endo-

BMI and Complications of Endoscopic

Submucosal Dissection scopic visualization of mesenteric fat during procedure or evidence of free air on abdominal X-ray examination after procedure), bleeding (melena/hematemesis or packed RBC transfusion), pneumonia (newly developed in post-procedural chest X-ray examination), atelectasis (newly developed in postprocedural chest $\mathrm{X}$-ray examination), fever $\left(>38^{\circ} \mathrm{C}\right)$, leukocytosis $(>11,000 / \mu \mathrm{L})$, and abdominal pain were assessed until discharge from the hospital $[22,23]$.

\section{Primary and Secondary Outcomes}

The primary outcome of this study was to clarify the effect of BMI on ESD-related complications including perforation, bleeding, and pneumonia. The secondary outcome was to evaluate the association between BMI and sedation-related complications such as desaturation, hypertension, and hypotension.

\section{Statistical Analysis}

Continuous variables are presented as mean \pm standard deviation, and categorical variables are expressed as number of patients (\%). Continuous variables were compared using ANOVA and categorical variables were compared using $\chi^{2}$ test or Fisher's exact test. Post hoc analysis was performed with Bonferroni correction to adjust for multiple comparisons. Unadjusted logistic regression analyses and adjusted logistic regression analyses were conducted to assess relationships between BMI and outcomes. Variables with $p<0.05$ in the univariable analysis and clinically important variables including age, sex, hypertension, diabetes, hepatitis, location of the lesion, and procedural time were considered as adjusted variables. The relationship between the probability of complications according to the BMI was expressed using the restricted cubic spline curve. All statistical tests were two tailed, and $p<0.05$ was considered statistically significant. All statistical analyses were performed using SAS (version 9.4, SAS Inc., Cary, NC, USA) and R (version 3.4.4, R Foundation for Statistical Computing, Vienna, Austria). 
Table 2. Procedure and clinicopathological details

\begin{tabular}{|c|c|c|c|c|}
\hline & $\begin{array}{l}\text { Normal }<23 \mathrm{~kg} / \mathrm{m}^{2} \\
(n=2,466)\end{array}$ & $\begin{array}{l}\text { Overweight } \\
23-24.9 \mathrm{~kg} / \mathrm{m}^{2}(n=2,117)\end{array}$ & $\begin{array}{l}\text { Obese } \geq 25 \mathrm{~kg} / \mathrm{m}^{2} \\
(n=2,680)\end{array}$ & $p$ value \\
\hline Procedure time, min & $42.4 \pm 30.0$ & $42.6 \pm 32.8$ & $43.0 \pm 32.3$ & 0.806 \\
\hline Sedation time, $\min$ & $48.4 \pm 31.0$ & $48.4 \pm 33.4$ & $49.1 \pm 34.0$ & 0.646 \\
\hline Recovery time, min & $23.9 \pm 9.8$ & $23.5 \pm 9.1$ & $23.7 \pm 9.5$ & 0.395 \\
\hline \multicolumn{5}{|l|}{ Sedative drugs } \\
\hline Propofol & $1,765(71.6)$ & $1,513(71.5)$ & $1,911(71.3)$ & \multirow[t]{3}{*}{0.982} \\
\hline Midazolam & $4(0.2)$ & $2(0.1)$ & $4(0.2)$ & \\
\hline Propofol + midazolam & $697(28.3)$ & $602(28.4)$ & $765(28.5)$ & \\
\hline \multicolumn{5}{|l|}{ Location of lesion } \\
\hline Upper & $262(10.6)$ & $205(9.7)$ & $295(11.0)$ & \multirow[t]{3}{*}{0.152} \\
\hline Middle & $618(25.1)$ & $518(24.5)$ & $604(22.5)$ & \\
\hline Lower & $1,586(64.3)$ & $1,394(65.9)$ & $1,781(66.5)$ & \\
\hline \multicolumn{5}{|l|}{ Gross type of lesion } \\
\hline Elevated & $1,895(76.9)$ & $1,649(77.9)$ & $2,095(78.2)$ & \multirow[t]{4}{*}{0.166} \\
\hline Flat & $228(9.3)$ & $160(7.6)$ & $202(7.5)$ & \\
\hline Depressed & $255(10.3)$ & $245(11.6)$ & $289(10.8)$ & \\
\hline Unknown & $88(3.6)$ & $63(3.0)$ & $94(3.5)$ & \\
\hline \multicolumn{5}{|l|}{ Submucosal fibrosis } \\
\hline F0 & $1,921(77.9)$ & $1,692(79.9)$ & $2,126(79.3)$ & \multirow[t]{4}{*}{0.439} \\
\hline $\mathrm{F} 1$ & $442(17.9)$ & $341(16.1)$ & $447(16.7)$ & \\
\hline $\mathrm{F} 2$ & $84(3.4)$ & $75(3.5)$ & $87(3.3)$ & \\
\hline Unknown & $19(0.8)$ & $9(0.4)$ & $20(0.8)$ & \\
\hline En bloc resection & $2,384(96.7)$ & $2,044(96.6)$ & $2,579(96.2)$ & 0.672 \\
\hline Pathologic tumor size, $\mathrm{mm}$ & $14.4 \pm 8.4$ & $14.1 \pm 8.3$ & $14.6 \pm 8.8$ & 0.181 \\
\hline \multicolumn{5}{|l|}{ Pathologic diagnosis } \\
\hline Cancer & $996(40.4)$ & 835 (39.4) & $1,069(39.9)$ & \multirow[t]{2}{*}{0.807} \\
\hline Adenoma & $1,470(59.6)$ & $1,282(60.6)$ & $1,611(60.1)$ & \\
\hline
\end{tabular}

Values are shown as mean \pm standard deviation or patients, $n(\%)$. F0, no fibrosis; F1, mild fibrosis; F2, severe fibrosis.

\section{Results}

\section{Patient Characteristics}

The mean value of BMI in all 7,263 patients was 24.2 $\pm 3.0 \mathrm{~kg} / \mathrm{m}^{2}$, and these patients were classified into the 3 groups: normal ( $n=2,466,33.7 \%)$, overweight $(n=2,117$, $29.1 \%)$, and obese $(n=2,680,36.9 \%)$ (Table 1$)$. The overweight and obese groups had a significantly higher incidence of ASA physical status III, hypertension, diabetes, and hepatitis and higher proportion of men than the normal group. Especially, the obese group had a significantly higher incidence of hypertension and diabetes than the overweight group.

\section{Procedure and Clinicopathological Details}

No significant difference was observed in procedurerelated variables and clinicopathological features of tumor between the 3 groups (Table 2).
ESD-Related Complications and Adjusted Logistic

Regression according to BMI

Table 3 shows the incidence of ESD complications and adjusted models (adjusted variables in model 1: age and sex; in model 2: age, sex, hypertension, diabetes, hepatitis, location of the lesion, and procedure time) according to the 3 BMI groups. There was a similar trend in adjusted models 1 and 2 .

The incidence of perforation was different among the 3 groups, which showed a significant decrease with an increase in BMI (normal: $8.2 \%$, overweight: $2.1 \%$, and obese: $1.0 \% ; p<0.001)$. Even after adjustment for all confounding variables (model 2), the risk of perforation significantly decreased in the overweight (odds ratio $[\mathrm{OR}]=$ $0.24,95 \%$ confidence interval [CI]: $0.17-0.33 ; p<0.001)$ and obese $(\mathrm{OR}=0.12,95 \% \mathrm{CI}: 0.08-0.18 ; p<0.001)$ groups compared to the normal group.

The incidence of pneumonia and leukocytosis after ESD was significantly higher in the overweight and obese 


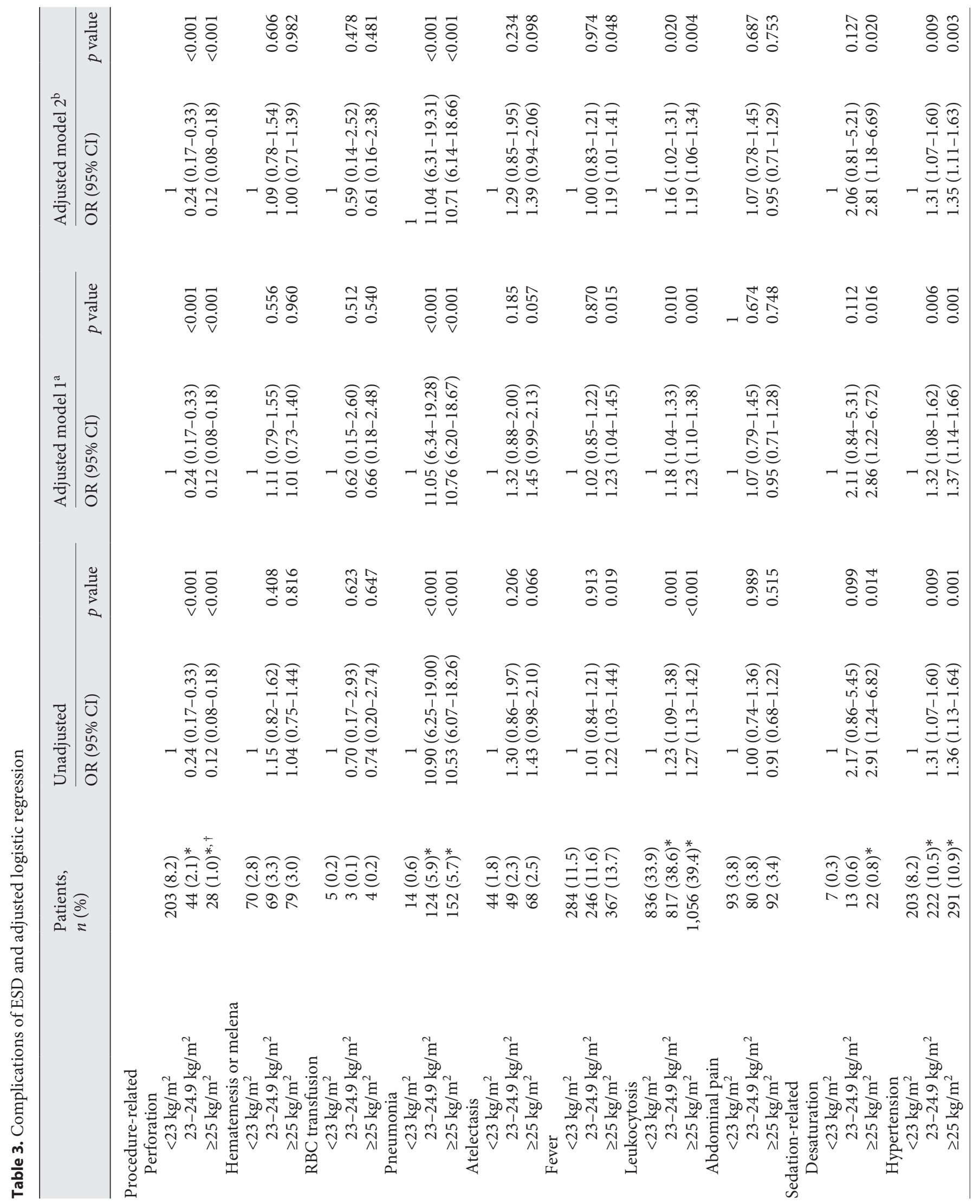




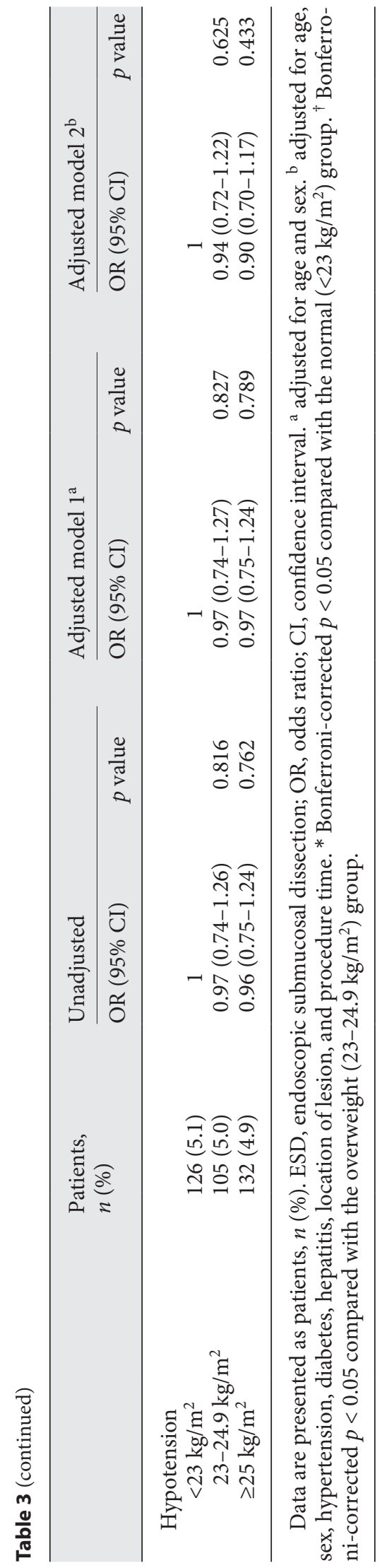

groups than in the normal group (Bonferroni corrected $p<0.001$ in both). In fact, the overweight $(\mathrm{OR}=11.04$, 95\% CI: 6.31-19.31; $p<0.001)$ and obese $(\mathrm{OR}=10.71$, 95\% CI: 6.14-18.66; $p<0.001)$ groups were associated with an increased risk of pneumonia compared to the normal group even after adjusting for all confounding variables. Likewise, the overweight $(\mathrm{OR}=1.16,95 \% \mathrm{CI}$ : $1.02-1.31 ; p=0.020)$ and obese $(\mathrm{OR}=1.19,95 \% \mathrm{CI}: 1.06-$ $1.34 ; p=0.004$ ) groups were associated with an increased risk of leukocytosis compared to the normal group in adjusted model 2.

The incidence of desaturation during sedation was significantly higher in the obese group than in the normal group ( 0.8 vs. $0.3 \%$; Bonferroni corrected $p=0.030$ ). The obese group had an increased risk of desaturation $(\mathrm{OR}=$ $2.81,95 \%$ CI: $1.18-6.69 ; p=0.020$ ) compared to the normal group when all confounding factors were adjusted. The episodes of hypertension during sedation were more frequent in the overweight (10.5\%) and obese (10.9\%) groups than in the normal group (8.2\%), and the risk of hypertension was significantly increased in the overweight $(\mathrm{OR}=1.31,95 \% \mathrm{CI}: 1.07-1.60 ; p=0.009)$ and obese groups (OR $=1.35,95 \% \mathrm{CI}: 1.11-1.63 ; p=0.003$ ) compared to the normal group in adjusted model 2 . The hospital stay after ESD was not different among the 3 groups (normal: $2.4 \pm 1.4$ days, overweight: $2.4 \pm 1.3$ days, and obese: $2.4 \pm 1.1$ days; $p=0.110$; data not shown).

\section{Probability of Major Complications according to BMI}

The probability of major complications (perforation and pneumonia), which showed significant differences among the 3 groups in Table 3 , was shown as a restricted cubic spline curve (Fig. 2). As BMI increased, there was a trend toward a decreased risk of perforation and an increased risk of pneumonia.

\section{Discussion}

This is the first study to directly assess the impact of BMI on ESD-related complications. The following were clarified by adjusted logistic regression analyses: (1) higher BMI ( $\left.\geq 23 \mathrm{~kg} / \mathrm{m}^{2}\right)$ was significantly associated with less perforation, (2) higher BMI ( $\left.\geq 23 \mathrm{~kg} / \mathrm{m}^{2}\right)$ significantly increased the risk of pneumonia and leukocytosis, and (3) obese $\left(\geq 25 \mathrm{~kg} / \mathrm{m}^{2}\right)$ patients had a significantly higher risk of intra-ESD desaturation and hypertension.

Prevalence of overweight and obesity has increased substantially in the past few decades in most Asian countries [16]. Generally, Asians have a higher percentage of 


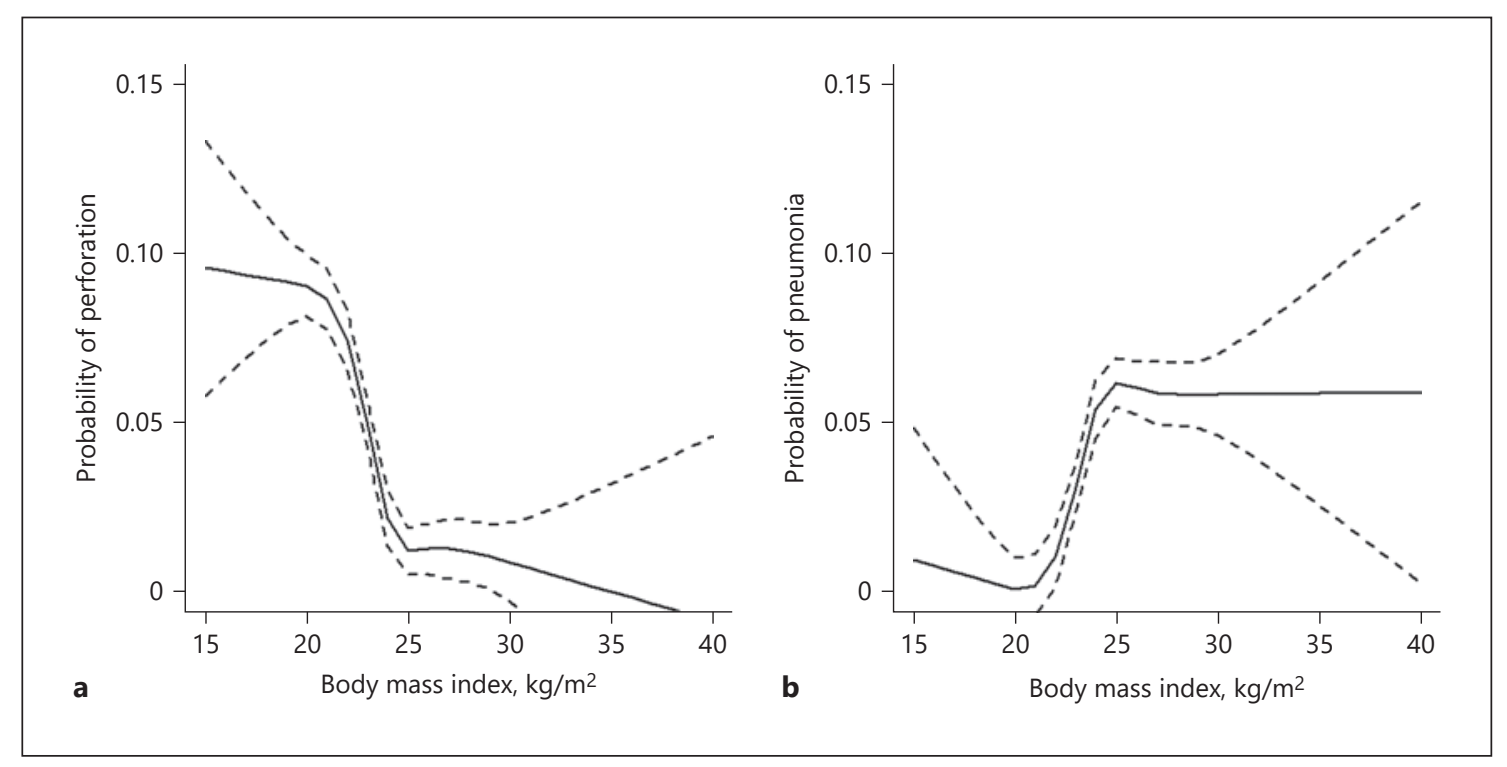

Fig. 2. Restricted cubic spline curve of the probability of (a) perforation or (b) pneumonia according to BMI. Black and dotted lines represent the estimated probability and 95\% CIs. CI, confidence interval.

body fat than Caucasians of the same age, sex, and BMI [20]. Therefore, obesity-related diseases (diabetes, hypertension, and cardiovascular disease) are more prevalent in Asian populations with BMI below the World Health Organization (WHO) cutoff point of $25 \mathrm{~kg} / \mathrm{m}^{2}$ [20]. Therefore, the Asia-Pacific classification of BMI was developed based on risk factors and morbidities; the cutoffs for overweight $\left(\geq 23 \mathrm{~kg} / \mathrm{m}^{2}\right)$ and obesity $\left(\geq 25 \mathrm{~kg} / \mathrm{m}^{2}\right)$ are lower than the WHO criteria [21]. In the current study, the Asia-Pacific classification of BMI was applied, with $29.1 \%$ patients being overweight and $36.9 \%$ being obese in a total of 7,263 patients. This is comparable to a previous study that reported $26.4 \%$ patients that were overweight and $38.8 \%$ that were obese out of 1,181 patients who had undergone gastric ESD [17]. These results suggest that more than $50 \%$ of patients scheduled for ESD can be overweight or obese, which calls for concern in these patients.

The 2 most common complications of ESD are perforation and bleeding $[6,8]$. In the current study, the incidence of perforation was $3.8 \%$, which is within the ranges of previously reported incidence of $1.2-5.2 \%[6-8,12$, 17]. Although previous studies reported no association between BMI and perforation $[6,17]$, our results showed that higher BMI was significantly associated with less perforation. One possible reason for the different results may be the large number of patients in our study compared to previous studies with 436 or 1,571 patients. After adjust-

BMI and Complications of Endoscopic Submucosal Dissection ment for all confounding factors, the risk of perforation decreased by $76 \%$ in patients that were overweight and $88 \%$ in obese patients compared to normal patients (Table 3). These results are comparable to those of a previous report, which showed that higher BMI decreased the risk of perforation during colonoscopy [19]. Histopathological changes (e.g., Helicobacter pylori infection, gastritis, and atrophy) or increased gastric wall thickness in obese patients can be a possible reason for less perforation in these patients $[24,25]$. The results of the association between BMI and post-ESD bleeding are inconsistent; 1 study found that a BMI $\geq 25 \mathrm{~kg} / \mathrm{m}^{2}$ predicted bleeding [15], while no association has been reported in other studies $[6,17]$. The incidence of bleeding, which was defined as occurrence of hematemesis or melena, and requiring transfusion in our study, was not different among the 3 BMI groups (Table 3), adding to the evidence of no association between BMI and post-ESD bleeding.

Gastric ESD is usually performed under sedation without tracheal intubation; thus, there is a risk of aspiration pneumonia. The incidence of pneumonia after ESD has been reported to range from 0.8 to $6.6 \%[8,9,14]$, and $3.9 \%$ of our patients developed pneumonia. Our study is the first to demonstrate that higher BMI significantly increased the risk of pneumonia. After adjusting for confounding factors, patients that were overweight or obese had an approximately 11 -fold increased risk of pneumonia compared to normal patients (Table 3 ). There may 
have been several contributing reasons for the higher incidence of pneumonia in obese patients. A previous study reported that obesity was independently associated with longer procedure times of ESD [17], and it is possible that this increased the incidence of pneumonia in obese patients. However, procedure time was not different among the 3 BMI groups in our study (Table 2). Another possible reason can be a higher prevalence of obstructive sleep apnea in obese patients because obstructive sleep apnea increases the risk of pulmonary aspiration during sleep [26]. In the current study, the incidence of desaturation was significantly higher in obese patients $(0.8 \%)$ than in normal patients $(0.3 \%)$ and the risk of desaturation increased by approximately 3 -fold in obese patients compared to normal patients even after adjustment for other confounding factors (Table 3). Therefore, more apnea episodes in obese patients during sedation, which is reflected by the increase of desaturation events in obese patients [27], may be the causative factor in the higher incidence of aspiration pneumonia.

Fever or leukocytosis can be induced by ESD complications such as perforation, bleeding, and pneumonia [9]. However, temporary inflammatory signs including fever and leukocytosis can be attributable to coagulation syndrome after ESD, which occurred in $7.1 \%$ of patients after gastric ESD [28]. In the current study, $12.4 \%$ of patients developed fever $\left(>38^{\circ} \mathrm{C}\right)$ and $37.3 \%$ of patients developed leukocytosis $(>11,000 / \mu \mathrm{L})$. Although the risk of fever was not different among the 3 BMI groups, the patients with higher BMI $\left(\geq 23 \mathrm{~kg} / \mathrm{m}^{2}\right)$ were associated with an increased risk of leukocytosis compared to normal patients even after adjustment of confounding factors (Table 3 ). Increased risk of leukocytosis in obese patients may be related to a higher incidence of pneumonia or coagulation syndrome in these patients; however, further studies are required to confirm this finding.

Hypertension or hypotension has been observed during ESD procedure under sedation [22], which may be due to inadequate sedation/analgesia or coexisting disease of patients. There was a baseline difference in coexisting hypertension among the $3 \mathrm{BMI}$ groups $(31.6 \%$ in normal, $42.7 \%$ in overweight, and $53.1 \%$ in obese; Table 1). However, higher BMI $\left(\geq 23 \mathrm{~kg} / \mathrm{m}^{2}\right)$ was associated with an increased risk of intra-ESD hypertension by $30 \%$ even after adjustment of hypertension with other confounders (Table 3).

The current study has several limitations, with the main drawback being the retrospective observational nature. However, to reduce confounding bias, logistic regression with adjustment for confounders was performed.
Second, long-term clinical outcomes of different BMI patients with complications were not evaluated in our study. Therefore, future studies with long-term follow-up are needed. Last, all patients included in our study were Koreans. Nonetheless, we included a large number of patients $(n>7,000)$ to ensure statistical reliability and the incidence of complications was similar to that seen in other studies of Asian participants [8,9]. Our results may be applicable to most Asian population although validation is required for other ethnic groups.

In conclusion, this study demonstrated a significant association between BMI and complications of gastric ESD, which was confirmed by adjusted logistic regression analyses. Obese patients had a significantly increased risk of pneumonia and leukocytosis despite having a decreased risk of perforation. Moreover, they also had a significantly higher risk for intra-ESD desaturation and hypertension. Therefore, efforts should be made to reduce aspiration with aspiration prophylaxis, and be cautious of desaturation and hypertension to take prompt management as needed in obese patients during ESD.

\section{Statement of Ethics}

This study was performed following approval from the Institutional Review Board and Hospital Research Ethics Committee of Severance Hospital, Yonsei University Health System, Seoul, Korea (number: 4-2019-0014), with informed consent form from the patients being waived off.

\section{Conflict of Interest Statement}

The authors disclose no conflicts.

\section{Funding Sources}

There is no funding to declare.

\section{Author Contributions}

Conceptualization: Na Young Kim, Hye Sun Lee, Ji Eun Kim, and So Yeon Kim. Data curation: Na Young Kim, Hye Sun Lee, Ki-Young Lee, Seung Yeon Choi, Hye Ji Joo, Ji Eun Kim, and So Yeon Kim. Methodology: Na Young Kim, Hye Sun Lee, Soyoung Jeon, Ji Eun Kim, and So Yeon Kim. Formal analysis: Hye Sun Lee. Writing - original draft: Na Young Kim, Hye Sun Lee, Ji Eun Kim, and So Yeon Kim. Writing - review \& editing: Na Young Kim, Hye Sun Lee, Ki-Young Lee, Soyoung Jeon, Seung Yeon Choi, Hye Ji Joo, Ji Eun Kim, and So Yeon Kim. 


\section{References}

1 Pimentel-Nunes P, Dinis-Ribeiro M, Ponchon T, Repici A, Vieth M, De Ceglie A, et al. Endoscopic submucosal dissection: European Society of Gastrointestinal Endoscopy (ESGE) guideline. Endoscopy. 2015;47(9): 829-54.

2 Chen H, Li B, Li L, Vachaparambil CT, Lamm $\mathrm{V}$, Chu Y, et al. Current status of endoscopic resection of gastric subepithelial tumors. Am J Gastroenterol. 2019;114(5):718-25.

3 Park YM, Cho E, Kang HY, Kim JM. The effectiveness and safety of endoscopic submucosal dissection compared with endoscopic mucosal resection for early gastric cancer: a systematic review and metaanalysis. Surg Endosc. 2011;25(8):2666-77.

4 Lian J, Chen S, Zhang Y, Qiu F. A meta-analysis of endoscopic submucosal dissection and EMR for early gastric cancer. Gastrointest Endosc. 2012;76(4):763-70.

5 Facciorusso A, Antonino M, Di Maso M, Muscatiello N. Endoscopic submucosal dissection vs endoscopic mucosal resection for early gastric cancer: a meta-analysis. World J Gastrointest Endosc. 2014;6(11):555-63.

6 Mannen K, Tsunada S, Hara M, Yamaguchi K, Sakata Y, Fujise T, et al. Risk factors for complications of endoscopic submucosal dissection in gastric tumors: analysis of 478 lesions. J Gastroenterol. 2010;45(1):30-6.

7 Toyokawa T, Inaba T, Omote S, Okamoto A, Miyasaka R, Watanabe K, et al. Risk factors for perforation and delayed bleeding associated with endoscopic submucosal dissection for early gastric neoplasms: analysis of 1,123 lesions. J Gastroenterol Hepatol. 2012;27(5): 907-12.

8 Oda I, Suzuki H, Nonaka S, Yoshinaga S. Complications of gastric endoscopic submucosal dissection. Dig Endosc. 2013;25 Suppl 1(Suppl 1):71-8.

9 Watari J, Tomita T, Toyoshima F, Sakurai J, Kondo T, Asano H, et al. The incidence of "silent" free air and aspiration pneumonia detected by CT after gastric endoscopic submucosal dissection. Gastrointest Endosc. 2012; 76(6):1116-23.
10 Ding X, Luo H, Duan H. Risk factors for perforation of gastric endoscopic submucosal dissection: a systematic review and metaanalysis. Eur J Gastroenterol Hepatol. 2019; 31(12):1481-8.

11 Kim M, Jeon SW, Cho KB, Park KS, Kim ES, Park CK, et al. Predictive risk factors of perforation in gastric endoscopic submucosal dissection for early gastric cancer: a large, multicenter study. Surg Endosc. 2013;27(4):13728.

12 Ohta $\mathrm{T}$, Ishihara $\mathrm{R}$, Uedo $\mathrm{N}$, Takeuchi $\mathrm{Y}$, Nagai K, Matsui F, et al. Factors predicting perforation during endoscopic submucosal dissection for gastric cancer. Gastrointest Endosc. 2012;75(6):1159-65.

13 Nam HS, Choi CW, Kim SJ, Kim HW, Kang $\mathrm{DH}$, Park SB, et al. Risk factors for delayed bleeding by onset time after endoscopic submucosal dissection for gastric neoplasm. Sci Rep. 2019;9(1):2674.

14 Park CH, Kim H, Kang YA, Cho IR, Kim B, Heo SJ, et al. Risk factors and prognosis of pulmonary complications after endoscopic submucosal dissection for gastric neoplasia. Dig Dis Sci. 2013;58(2):540-6.

15 Okada K, Yamamoto Y, Kasuga A, Omae M, Kubota M, Hirasawa T, et al. Risk factors for delayed bleeding after endoscopic submucosal dissection for gastric neoplasm. Surg Endosc. 2011;25(1):98-107.

16 Ramachandran A, Snehalatha C. Rising burden of obesity in Asia. J Obes. 2010;2010: 868573.

17 Kang D, Ha SE, Park JM, Yoon SB, Lee HH, Lim $\mathrm{CH}$, et al. Body Mass Index and clinical outcomes from endoscopic submucosal dissection of gastric neoplasia. Dig Dis Sci. 2017; 62(6):1657-65.

18 Wani S, Azar R, Hovis CE, Hovis RM, Cote GA, Hall M, et al. Obesity as a risk factor for sedation-related complications during propofol-mediated sedation for advanced endoscopic procedures. Gastrointest Endosc. 2011;74(6):1238-47.
19 Hamdani U, Naeem R, Haider F, Bansal P, Komar M, Diehl DL, et al. Risk factors for colonoscopic perforation: a population-based study of 80,118 cases. World J Gastroenterol. 2013;19(23):3596-601.

20 WHO Expert Consultation. Appropriate body-mass index for Asian populations and its implications for policy and intervention strategies. Lancet. 2004;363(9403):157-63.

21 World Health Organization ROftWP. The Asia-Pacific perspective: redefining obesity and its treatment. Sydney: Health Communications Australia; 2000.

22 Kim JE, Shin CS, Lee YC, Lee HS, Ban M, Kim SY. Beneficial effect of intravenous magnesium during endoscopic submucosal dissection for gastric neoplasm. Surg Endosc. 2015; 29(12):3795-802.

23 Kim JE, Choi JB, Koo BN, Jeong HW, Lee BH, Kim SY. Efficacy of intravenous lidocaine during endoscopic submucosal dissection for gastric neoplasm: a randomized, doubleblind, controlled study. Medicine. 2016; 95(18):e3593.

24 Olefson S, Moss SF. Obesity and related risk factors in gastric cardia adenocarcinoma. Gastric Cancer. 2015;18(1):23-32.

25 Rawlins L, Rawlins MP, Teel D 2nd. Human tissue thickness measurements from excised sleeve gastrectomy specimens. Surg Endosc. 2014;28(3):811-4.

26 Beal M, Chesson A, Garcia T, Caldito G, Stucker F, Nathan CO. A pilot study of quantitative aspiration in patients with symptoms of obstructive sleep apnea: comparison to a historic control group. Laryngoscope. 2004; 114(6):965-8.

27 Peppard PE, Ward NR, Morrell MJ. The impact of obesity on oxygen desaturation during sleep-disordered breathing. Am J Respir Crit Care Med. 2009;180(8):788-93.

28 Lee H, Cheoi KS, Chung H, Park JC, Shin SK, Lee SK, et al. Clinical features and predictive factors of coagulation syndrome after endoscopic submucosal dissection for early gastric neoplasm. Gastric Cancer. 2012;15(1):83-90.
BMI and Complications of Endoscopic Submucosal Dissection 